\title{
Placental and Other Perinatal Risk Factors for Chronic Lung Disease in Very Low Birth Weight Infants
}

\author{
RAYMOND W. REDLINE, DEANNE WILSON-COSTELLO, AND MAUREEN HACK \\ Departments of Pathology [R.W.R] and Pediatrics [D.W-C., M.H.], Rainbow Babies and Children's \\ Hospital, University Hospitals of Cleveland, and Case Western Reserve University School of Medicine, \\ Cleveland, $\mathrm{OH} 44106$, U.S.A.
}

\begin{abstract}
To clarify the relationship between chorioamnionitis and chronic lung disease (CLD) in very low birth weight (VLBW) infants, we performed a retrospective cohort study of all inborn patients between 1995-1997 with gestational age (GA) less than $32 \mathrm{wk}$, birth weight less than $1.5 \mathrm{~kg}$, survival to $36 \mathrm{wk}$ adjusted GA, and placentas submitted to pathology $(n=371)$. Racial distribution as defined by the mother was $40 \%$ white $/ 60 \%$ nonwhite. Prevalence of CLD, defined as $\mathrm{O}_{2}$ dependence at $36 \mathrm{wk}$ adjusted GA, was $30 \%$. In a preliminary analysis GA and birth weight for GA (standard deviations from the mean, Z-score), considered together, were inversely related to CLD. After adjustment for GA and Z-score, other risk factors for CLD were white race, acute respiratory distress, pulmonary air leak, patent ductus arteriosus, and septicemia. Two placental lesions were inversely related to CLD: histologic chorioamnionitis and acute atherosis (a placental indicator of preeclampsia). Following multivariate
\end{abstract}

\section{ABSTRACT}

analysis, independent risk factors for CLD were GA (OR, 0.6; $95 \% \mathrm{CI}=0.5,0.7)$, birthweight for $\mathrm{GA}(\mathrm{OR}, 0.4 ; 95 \% \mathrm{CI}=0.3$, $0.6)$, white race $(\mathrm{OR}, 1.9 ; 95 \% \mathrm{CI}=1.0,3.3)$, patent ductus arteriosus (OR, 2.0; 95\% CI = 1.0, 3.5), and pulmonary air leak $(\mathrm{OR}, 3.0 ; 95 \% \mathrm{CI}=1.3,7.1)$. Acute atherosis was inversely related to CLD (OR, 0.2; 95\% CI $=0.1,0.8)$. Chorioamnionitis was stratified by subtype and again no association with CLD was seen in the population as a whole. Finally, chorioamnionitis of all subtypes tended to be increased in white infants and decreased in black infants with CLD. This dichotomy was not explained by differences in death rates, acute respiratory distress, intubation on d 2 of life, or total duration of assisted ventilation. We conclude that while chorioamnionitis was not a risk factor for CLD in our total population, racial differences in its relationship to CLD are worthy of further study. (Pediatr Res 52: 713-719, 2002)
Chronic lung disease (CLD) is a major cause of morbidity and mortality among very low birthweight (VLBW, $<1.5 \mathrm{~kg}$ ) infants. Some studies have implicated chorioamnionitis as a risk factor for CLD (1-5). Critical parameters in considering such a relationship include potential confounders such as differences in gestational age and weight for gestational age (fetal growth restriction), the definitions of chorioamnionitis used, and the changing nature of CLD itself. With respect to CLD, recent improvement in the overall survival of extremely low birth weight $(<1000 \mathrm{~g})$ infants associated with surfactant, antenatal corticosteroids, and changes in early ventilator management has led to the emergence of a "new" CLD characterized by less airway injury and more pulmonary parenchymal disease $(6,7)$. In this study we addressed these issues by examining different clinical and histologic subtypes of chorio-

Received May 29, 2001; Accepted April 17, 2002.

Correspondence: Raymond W. Redline, MD, Department of Pathology, University Hospitals of Cleveland, 11100 Euclid Avenue, Cleveland $\mathrm{OH}$ 44106; e-mail: raymond.redline@uhhs.com

DOI: 10.1203/01.PDR.0000032156.73790.E0 amnionitis together with other potential placental and perinatal risk factors for CLD in a recent cohort of VLBW infants.

\section{MATERIALS AND METHODS}

Population. This was a cohort study assessing placental and other perinatal risk factors for CLD in VLBW infants of less than 32 wk GA born between 1995-1997 at the MacDonald Hospital for Women at University Hospitals of Cleveland. CLD was defined as oxygen dependence at $36 \mathrm{wk}$ corrected gestational age. The final study sample of 371 infants was derived from a total population of 490 inborn VLBW infants after the following exclusions: GA greater than $32 \mathrm{wk}$ at birth $(n=38)$, death before $36 \mathrm{wk}$ adjusted GA $(n=59)$, and lack of placental pathology $(n=22)$. The 22 patients lacking placental pathology included 5 with CLD and 17 without CLD. Demographic data (birth weight, GA, and days of oxygen dependence, ventilator dependence, and postnatal steroid therapy) did not differ for infants with and without placental pathology in each group (data not shown). All aspects of the data collection process were in accord with guidelines of the 
Office of Human Subject Research of the National Institutes of Health and had the approval of the University Hospitals Institutional Review Board.

Clinical and Pathologic Data. Obstetrical and neonatal data were extracted from a comprehensive database of all VLBW infants admitted to the neonatal intensive care unit at our institution since 1977 (8). All placentas were examined and processed using a standard protocol with five sections per placenta including two membrane rolls, two sections of umbilical cord, and three parenchymal sections each including the chorionic plate. Placental reports and slides were blindly reviewed and reclassified by a single observer (RWR) using a previously described hierarchical classification scheme (9). Risk factors evaluated in this study included:

Maternal: mean age, age $>35 \mathrm{y}$, history of infertility, previous premature birth, multiple pregnancy, premature rupture of membranes, preeclampsia, clinical chorioamnionitis, prenatal care, genitourinary infections during pregnancy, oligohydramnios, clinical abruption, chronic vaginal bleeding, tocolytic therapy, antenatal steroids

Placental: histologic chorioamnionitis (maternal response), histologic chorioamnionitis (fetal response), villous edema, findings suggestive of maternal underperfusion, markedly increased syncytial knots, multiple villous infarcts, acute atherosis, thin umbilical cord, chorionic vessel thrombi, perivillous fibrin deposition, chronic deciduitis, decidual plasma cells, membrane hemosiderin, recent retroplacental hemorrhage, monochorionic twinning

Neonatal: birthweight, gestational age, birth weight for GA (Z-score), male sex, white race, Apgar $<6,1 \mathrm{~min}$, Apgar $<6,5$ min, acute respiratory distress, Surfactant therapy, patent ductus arteriosus, pulmonary air leak, pulmonary hemorrhage, pneumonia, low thyroxine, septicemia, severe cranial ultrasound abnormalities, necrotizing enterocolitis, hyperbilirubinemia

Our definitions of these risk factors have been previously published $(8,10)$. Gestational age was the best obstetric estimate (taking into account last menstrual period. Ultrasound, and/or early pelvic examination). Birth weight for GA was measured by Z-score (number of standard deviations from the mean for GA) using neonatal data derived from a population similar to our own (11). Race was maternally defined. Acute respiratory distress was defined as oxygen dependence at $2 \mathrm{~d}$ of age. Hypothyroxinemia was determined by the state newborn screening test. Patent ductus arteriosus was defined by clinical signs (murmur, bounding pulse, active precordium) with or without further investigation. Pulmonary air leak was the presence of air in the pleural space, mediastinum, or tissue spaces of the lung by $\mathrm{x}$-ray. Septicemia was a positive blood culture. Acute atherosis was medial fibrinoid necrosis and foam cells affecting decidual arteries of the basal plate or membrane role. Clinical chorioamnionitis was defined by maternal fever in the presence of abdominal tenderness, fetal tachycardia, maternal leukocytosis, and/or foul smelling amniotic fluid. Histologic chorioamnionitis was separated into maternal and fetal inflammatory components and subclassified by intensity of the inflammatory infiltrate. Maternal intensity, scored in the worst area of the chorionic plate), was scored as follows: mild-rare neutrophils $(<10 /$ high power field), moder- ate-intermediate neutrophils (11-30/high power field), and severe-abundant neutrophils ( $>30 /$ high power field). Fetal intensity, based on the intensity of inflammation in the most severely affected chorionic plate vessel, was scored as follows: mild-scattered rare neutrophils, moderate-intermediate neutrophils, and severe-near confluent neutrophils associated with attenuation of the vessel wall.

Statistical Analysis. $\chi^{2}$ and Fisher exact tests were used for categorical data with significance set at $p=0.050$. Continuous variables were compared using the two-tailed $t$ test with significance set at $p=0.050$. Adjusted analyses were performed after correction for GA and birth weight for GA. All individual risk factors significant in the adjusted analyses were entered into a multivariate logistic regression model along with GA and birth weight for GA to identify independent predictors of CLD.

\section{RESULTS}

Selected characteristics of the study groups are listed in Table 1. Patients with CLD had significantly lower birth weight, were born at an earlier GA, and were more acutely ill before the development of CLD as estimated by mean days of oxygen, assisted ventilation, and postnatal steroid therapy. Severe fetal growth restriction (Z-score $<-2 \mathrm{SD}$ ), male sex, multiple pregnancy, preeclampsia, administration of antenatal steroids, and surfactant treatment were comparable in the two groups.

In a preliminary analysis gestational age (GA) was inversely related to CLD (OR, 0.6; 95\% CI $=0.5,0.7)$. Since low birth weight for GA (Z-score) was more frequent in infants of higher GA (data not shown), we analyzed it together with GA in a logistic regression model. This analysis showed strong independent inverse relationships for both variables with CLD (GA: OR, 0.5; 95\% CI $=0.4,0.6$ and Z-score: OR, 0.5; 95\% $\mathrm{CI}=0.3,0.6)$. Although not significant alone, severe fetal growth restriction (Z-score $<-2.0 \mathrm{SD}$ ) when adjusted for GA was also a strong positive risk factor for CLD (OR, 17.7; 95\%

Table 1. Selected characteristics of the study population

\begin{tabular}{lcc}
\hline & $\begin{array}{c}\text { CLD } \\
(n=112)\end{array}$ & $\begin{array}{c}\text { No CLD } \\
(n=259)\end{array}$ \\
\hline Mean birth weight $(\mathrm{g})$ & $813 \pm 212^{*} \dagger$ & $1114 \pm 238$ \\
Mean gestational age (wk) & $26.1 \pm 2.1^{*}$ & $28.3 \pm 2.0$ \\
Mean Z-score (SD) + & $-0.01 \pm 1.12$ & $0.03 \pm 1.03$ \\
Mean Oxygen (d) & $103 \pm 40^{*}$ & $21 \pm 21$ \\
Mean Ventilation (d) & $40 \pm 30^{*}$ & $11 \pm 12$ \\
Mean Postnatal Steroids (d) & $34 \pm 37^{*}$ & $7 \pm 13$ \\
Gestational age $\leq 25$ wk & $43(38)^{*} \S$ & $20(8)$ \\
Z-score $<-2.0$ & $7(6)$ & $10(4)$ \\
Male sex & $60(54)$ & $137(53)$ \\
Multiple pregnancy & $26(23)$ & $63(24)$ \\
Preeclampsia & $22(20)$ & $49(19)$ \\
Antenatal steroids & $73(65)$ & $168(65)$ \\
Surfactant & $88(79)$ & $132(51)$ \\
\hline
\end{tabular}

$* p<0.050$.

$\dagger$ Mean + SD

$\$ \mathrm{Z}$-score $=\mathrm{SD}$ from mean birthweight for gestational age.

$\S$ Number positive ( $\%$ positive). 
$\mathrm{CI}=4.7,67.0)$. In light of these data, subsequent analyses were adjusted for both GA and Z-score.

Table 2 lists the other perinatal and placental risk factors that were significantly related to CLD in either the unadjusted or adjusted analyses. Significant in both analyses were acute respiratory distress, pulmonary air leak, patent ductus arteriosus, and septicemia. One minute Apgar score and thyroxine level were no longer significant after adjustment. Histologic chorioamnionitis was unrelated to CLD in the unadjusted analysis and inversely related to CLD after adjustment. Other associations emerging after adjustment were acute atherosis of decidual arteries (inversely related to CLD) and white race (directly related to CLD).

All risk factors significant in the adjusted analysis were entered along with GA and Z-score in a multivariate model (Table 3). GA and birth weight for GA remained significant risk factors for CLD along with white race, pulmonary air leak, and patent ductus arteriosus. Acute atherosis showed a negative association with CLD. Septicemia showed a borderline positive association $(p=0.054)$. Respiratory distress and histologic chorioamnionitis dropped out of the model.

In light of controversy in the literature regarding chorioamnionitis as a risk factor for CLD we performed additional analyses examining specific clinical and pathologic subtypes of chorioamnionitis. Histologic chorioamnionitis was separated into maternal and fetal inflammatory responses and each was further subdivided on the basis of severity as described in the Materials and Methods. No significant relationship of clinical chorioamnionitis or any subtype of histologic chorioamnionitis to CLD was observed in analyses adjusted for GA alone, GA and Z-score, and GA, Z-score, plus all of the significant neonatal risk factors identified in the multivariate model (Table 4).

The relationship of chorioamnionitis to CLD was further explored after stratification by race (Table 5). It should first be noted that chorioamnionitis of all subtypes was much more common in nonwhite infants. In white infants clinical chorioamnionitis showed a borderline significant positive association with CLD $(p=0.059)$ and all subtypes of histologic chorio-

Table 2. Risk factors for chronic lung disease, before and after adjustment for GA and birth weight for GA (Z-score)

\begin{tabular}{|c|c|c|c|c|}
\hline & $\begin{array}{c}\text { CLD } \\
(n=112)\end{array}$ & $\begin{array}{l}\text { No CLD } \\
(n=259)\end{array}$ & $\begin{array}{c}\text { Adjusted } \\
\text { OR }\end{array}$ & $95 \% \mathrm{CI}^{*}$ \\
\hline \multicolumn{5}{|l|}{ Chorioamnionitis } \\
\hline Histologic (any) & $52(46) \dagger$ & $117(45)$ & 0.7 & $0.4,0.9$ \\
\hline Clinical & $15(13)$ & $28(11)$ & 1.0 & $0.4,2.1$ \\
\hline \multicolumn{5}{|l|}{ Other placental } \\
\hline Acute atherosis & $8(7)$ & $31(12)$ & 0.3 & $0.1,1.0$ \\
\hline \multicolumn{5}{|l|}{ Other clinical } \\
\hline White race & $49(44)$ & $98(38)$ & 2.0 & $1.2,3.5$ \\
\hline Apgar $<6,1 \mathrm{~min}$ & $83(74) \div$ & $135(52)$ & 1.5 & $0.8,2.6$ \\
\hline Acute respiratory distress & $109(97) \div$ & $199(77)$ & 3.9 & $1.1,13.4$ \\
\hline Pulmonary air leak & $26(23) t$ & $10(4)$ & 3.4 & $1.5,7.8$ \\
\hline Patent ductus arteriosus & $67(60) \div$ & $65(25)$ & 2.3 & $1.4,4.0$ \\
\hline Septicemia & $65(58) \div$ & $80(31)$ & 1.9 & $1.1,3.3$ \\
\hline Low thyroxine & $31(28) \div$ & $47(18)$ & 1.2 & $0.6,2.2$ \\
\hline
\end{tabular}

* Adjusted for GA and Z-score.

$\dagger$ Number positive ( $\%$ positive).

$\$ p<0.050$, unadjusted.
Table 3. Multivariate analysis of risk factors for chronic lung disease

\begin{tabular}{lll}
\hline & OR & $95 \%$ CI \\
\hline Gestational age & 0.6 & $0.5,0.7$ \\
Birth weight for dates (Z-score) & 0.4 & $0.3,0.6$ \\
White race & 1.9 & $1.0,3.3$ \\
Pulmonary air leak & 3.0 & $1.3,7.1$ \\
Patent ductus arteriosus & 2.0 & $1.1,3.5$ \\
Acute atherosis & 0.2 & $0.1,0.8$ \\
Septicemia & 1.7 & $1.0,3.1 *$ \\
Acute respiratory distress & 2.5 & $0.7,8.9$ \\
Histologic chorioamnionitis & 0.7 & $0.4,1.3$ \\
\hline
\end{tabular}

$* p=0.054$

amnionitis were more frequent in the CLD group. Conversely, in nonwhite infants CLD was significantly decreased with severe fetal histologic chorioamnionitis (OR, $0.2 ; 95 \% \mathrm{CI}=$ $0.4,0.7)$ and other measures of clinical and histologic chorioamnionitis were all less common in the CLD group. To further examine this relationship we excluded nine nonwhite infants of other racial backgrounds and looked in more detail at infants identified as either black or white by their mothers.

One explanation for decreased CLD in black infants with chorioamnionitis could be increased early neonatal death in infected gestations. To address this hypothesis, we examined all inborn live births of less than 28 wk gestation admitted to the NICU, stratifying for presence or absence of clinical chorioamnionitis as a predictor of death before $36 \mathrm{wk}$ corrected GA. Deaths were rare in births after 28 wk and only occurred in infants without CA. Only clinical chorioamnionitis could be evaluated in this analysis because histologic data were unavailable in many cases. Interestingly, although not achieving statistically significance, we observed the same racially dichotomous relationship for death at less than $36 \mathrm{wk}$ corrected GA as was observed for CLD. Death was less frequent in black infants with clinical chorioamnionitis $(12 \%$, versus $20 \%$ without chorioamnionitis) and slightly more frequent in white infants with clinical chorioamnionitis $(20 \%$, versus $16 \%$ without chorioamnionitis). An inverse relationship between neonatal death and chorioamnionitis in extremely premature infants has been previously described (12).

To better understand the relationships between race, chorioamnionitis, and CLD we evaluated other measures of clinical respiratory status in black and white infants stratified by histologic chorioamnionitis and gestational age (Table 6). No differences in the frequency of acute respiratory distress, duration of ventilation, or duration of oxygen supplementation were noted for either black or white infants born at $28 \mathrm{wk}$ or less. CLD was again less common in black infants and more common in white infants with histologic chorioamnionitis. Restricting the analysis to "sicker" infants who remained intubated on day 2 of life accentuated the differential effects of chorioamnionitis and the inverse relationship between histologic chorioamnionitis and CLD achieved statistical significance for black infants. For infants born after 28 wk there was no relationship between histologic chorioamnionitis and CLD in black or white infants. However, trends were noted suggesting less acute respiratory distress and a shorter duration of 
Table 4. Association of subtypes of chorioamnionitis with chronic lung disease

\begin{tabular}{|c|c|c|c|c|c|c|c|}
\hline \multirow{2}{*}{$\begin{array}{l}\text { Chorioamnionitis } \\
\text { subtype }\end{array}$} & \multirow[b]{2}{*}{ Prevalence } & \multicolumn{2}{|c|}{ Adj. GA* } & \multicolumn{2}{|c|}{ Adj. GA \& Z-score $\uparrow$} & \multicolumn{2}{|c|}{$\begin{array}{l}\text { Adj. GA, Z-score, } \& \\
\text { Neonatal risk factors } \leftarrow\end{array}$} \\
\hline & & OR & $95 \% \mathrm{CI}$ & OR & $95 \% \mathrm{CI}$ & OR & $95 \% \mathrm{CI}$ \\
\hline Clinical & $11 \%$ & 1.0 & $0.5,2.0$ & 1.0 & $0.4,2.1$ & 1.1 & $0.5,2.3$ \\
\hline \multicolumn{8}{|l|}{ Histologic, maternal } \\
\hline Any & $46 \%$ & 0.6 & $0.4,1.0$ & 0.7 & $0.4,1.2$ & 0.8 & $0.4,1.4$ \\
\hline Severe & $5 \%$ & 0.7 & $0.3,2.1$ & 0.6 & $0.2,1.9$ & 0.7 & $0.2,2.3$ \\
\hline \multicolumn{8}{|l|}{ Histologic, fetal } \\
\hline Any & $39 \%$ & 0.7 & $0.4,1.1$ & 0.7 & $0.4,1.3$ & 0.9 & $0.5,1.5$ \\
\hline Severe & $11 \%$ & 0.4 & $0.2,1.0$ & 0.4 & $0.2,1.1$ & 0.6 & $0.2,1.5$ \\
\hline
\end{tabular}

* Adjusted for gestational age (GA).

$\dagger$ Adjusted for GA and Z-score.

$\$$ Adjusted for GA, Z-score, and other significant neonatal risk factors (air leak, patent ductus arteriosus, and septicemia).

Table 5. Association of chorioamnionitis with chronic lung disease after stratification by race*

\begin{tabular}{|c|c|c|c|c|c|c|}
\hline \multirow{2}{*}{$\begin{array}{c}\text { Chorioamnionitis } \\
\text { subtype }\end{array}$} & \multicolumn{3}{|c|}{ White infants $(n=147) \dagger$} & \multicolumn{3}{|c|}{ Non-white infants $(n=224) !$} \\
\hline & Prevalence $(\%)$ & $\mathrm{OR}$ & $95 \% \mathrm{CI}$ & Prevalence $(\%)$ & OR & $95 \% \mathrm{CI}$ \\
\hline Clinical & 4 & 5.4 & $1.0,30.7 \S$ & 15 & 0.7 & $0.3,1.7$ \\
\hline \multicolumn{7}{|l|}{ Histologic, maternal } \\
\hline Any & 31 & 1.1 & $0.5,2.5$ & 50 & 0.6 & $0.3,1.2$ \\
\hline Severe & 3 & 1.3 & $0.1,15.1$ & 6 & 0.3 & $0.1,2.1$ \\
\hline \multicolumn{7}{|l|}{ Histologic, fetal } \\
\hline Any & 27 & 1.3 & $0.5,3.2$ & 43 & 0.6 & $0.3,1.2$ \\
\hline Severe & 7 & 1.5 & $0.4,6.3$ & 12 & 0.2 & $0.4,0.79$ \\
\hline
\end{tabular}

* Adjusted for gestational age (GA) and birth weight for GA (Z-score).

$\dagger$ Prevalence CLD $=33 \%$.

$\ddagger$ Prevalence $\mathrm{CLD}=28 \%$.

$\S p=0.059$.

I $p<0.050$.

Table 6. Clinical respiratory status in black and white infants stratified by chorioamnionitis and birthweight

\begin{tabular}{|c|c|c|c|c|c|c|c|}
\hline Race & $\begin{array}{c}\text { Histologic } \\
\text { chorioamnionitis } \\
\text { (any) }\end{array}$ & $n$ & $\begin{array}{l}\text { Acute } \\
\text { respiratory } \\
\text { distress }\end{array}$ & $\begin{array}{l}\text { Duration } \mathrm{O}_{2} \\
\quad \text { (days) }\end{array}$ & $\begin{array}{c}\text { Duration ventilation } \\
\text { (days) }\end{array}$ & CLD & $\begin{array}{c}\text { CLD } \\
\text { (Intubated d 2)* }\end{array}$ \\
\hline \multicolumn{8}{|c|}{$\begin{array}{l}28 \text { Weeks or less } \\
\text { gestational age }\end{array}$} \\
\hline \multirow[t]{2}{*}{ Black } & + & 58 & $55(92)$ & $68 \pm 41$ & $30 \pm 18$ & $23(40)$ & $23 / 57(40)$ \\
\hline & - & 47 & $43(92)$ & $79 \pm 41$ & $33 \pm 21$ & $27(57)$ & $27 / 45(60) \dagger$ \\
\hline White & + & 27 & $26(96)$ & $73 \pm 33$ & $28 \pm 17$ & $16(59)$ & $16 / 25(64)$ \\
\hline \multirow[t]{2}{*}{ Black } & + & 40 & $25(63)$ & $12 \pm 22$ & $5 \pm 9$ & $3(8)$ & 2/14 (14) \\
\hline & - & 70 & $48(69)$ & $19 \pm 40$ & $10 \pm 28$ & $7(10)$ & $7 / 31(23)$ \\
\hline \multirow[t]{2}{*}{ White } & + & 17 & $16(94)$ & $31 \pm 38$ & $10 \pm 13$ & $3(18)$ & 3/11 (27) \\
\hline & - & 65 & $49(75)$ & $24 \pm 28$ & $10 \pm 10$ & $12(19)$ & $11 / 44(25)$ \\
\hline
\end{tabular}

* Analysis restricted to neonates intubated on day 2 of life (number with CLD/total intubated on day 2).

$\dagger p=0.049$.

assisted ventilation in black infants with chorioamnionitis and more acute respiratory distress and a longer duration of assisted ventilation in white infants with chorioamnionitis.

Finally, we surveyed risk factors in the white and black populations that might help explain different outcomes with chorioamnionitis (data not shown). In this analysis mothers of black infants were younger, had more antenatal genitourinary tract infections, were more likely to have had a vaginal delivery, and were less likely to have received prenatal care, antenatal tocolytics, or corticosteroids. Mothers of white infants were more likely to have been of advanced maternal age, to have had a history of infertility, and have carried a multiple gestation. None of the neonatal variables studied differed in the two populations.

\section{DISCUSSION}

Chronic lung disease occurs in $10 \%$ to $40 \%$ of VLBW infants and is a major cause of long term pulmonary complications including recurrent respiratory infections, reactive airway disease, and abnormal pulmonary function (13-15). In addition to respiratory disease, survivors with CLD also have 
an increased risk of cerebral palsy, mental retardation, and other less serious motor and cognitive disorders $(16,17)$. CLD, in most cases, correlates with a pathologic process known as bronchopulmonary dysplasia (BPD). BPD was originally described as an injury pattern primarily affecting large airways caused by the deleterious effects of hyperoxia and barotrauma on the immature lung (18). While these factors continue to play an important role in CLD, recent reports from the era of antenatal steroids and surfactant therapy have emphasized a new pattern of BPD $(6,19,20)$. This new BPD is related to developmental abnormalities in alveolar crest formation leading to alveolosaccular and capillary hypoplasia and focal interstitial fibrosis. Investigators have stressed the role of extreme immaturity, nutritional factors, and, in particular, inflammatory mediators in the genesis of this new BPD (21, 22).

CLD may be defined by a variety of criteria including duration of ventilator dependence, oxygen requirements, radiographic appearance, and pulmonary function abnormalities. Although it is generally agreed that a definition relying on pulmonary function is impractical in the intensive care unit setting, some authors have advocated a greater reliance on radiographic features (23). The consensus criterion in most common usage at this time and the one adopted for this study is oxygen dependence at $36 \mathrm{wk}$ corrected gestational age (24).

Strengths of our study include the relatively recent study period (1995-1997) encompassing the new BPD, accrual of cases from a single institution with a longitudinal database, and inclusion of a comprehensive placental analysis using criteria already validated in previous outcome studies of VLBW infants $(9,17)$. Weaknesses include relatively small sample size and lack of detailed information regarding the early neonatal course $\left(\mathrm{CO}_{2}\right.$ levels, fluid requirements, cortisol levels, and indexes of overall illness such as CRIB or SNAP risk scores) (25-29).

Our study confirmed a number of previously described neonatal risk factors for CLD including gestational age, patent ductus arteriosus, pulmonary air leak, and septicemia $(26,30)$. Other previously reported risk factors significant at the univariate, but not the multivariate, level in our study included decreased thyroxine, early respiratory distress, and low one minute Apgar score (30-32). Previously described risk factors for CLD not significant in our study included male sex, and premature rupture of membranes (33-35). We did find male sex to be significantly increased in infants with CLD in the 1000-1499 g birth weight subgroup (results not shown).

The relationships between fetal growth restriction, maternal hypertension, and lung disease are controversial and complicated by significant overlap between fetal growth restriction and preeclampsia. We found an inverse relationship between birth weight for gestational age (Z-score) and CLD after adjustment for GA. Severe fetal growth restriction as defined by a Z-score more than $2.0 \mathrm{SD}$ below the mean for GA was a highly significant risk factor for CLD, but only after adjustment for GA. Previous studies have reported both positive and negative relationships between fetal growth restriction and neonatal lung disease (36-39). The underlying mechanisms by which growth restriction affects lung function are speculative, but might be related to some of the well known nutritional and metabolic abnormalities in these patients $(40,41)$.

Preeclampsia is one of several pregnancy complications in which pulmonary maturity may be accelerated as measured by amniotic fluid phospholipids (45). In one well-controlled study mild-moderate maternal hypertension was associated with a significant decrease in respiratory distress syndrome $(42,43)$. Clinical preeclampsia was not associated with CLD in our study. However, CLD was decreased in infants with acute atherosis, a placental finding found in a subgroup of preeclamptic mothers (44). Acute atherosis, also known as fibrinoid necrosis of decidual arteries, has been associated with excessive amounts of circulating oxidized lipoproteins and increases in local concentrations of lipoprotein (a) and PDGF- $\beta$ (45-47). It seems to be a marker for the fulminant acute phase of maternal preeclampsia and is seen in approximately $25 \%$ of preeclamptic placentas (unpublished data). One factor that might explain a deceased risk of CLD in infants with acute atherosis is the association of fulminant maternal preeclampsia with fetal neutropenia (48). Neutropenia has a complex relationship with lung injury which can be summarized as follows: neutropenia before birth may limit injury by reducing lung neutrophils while neutropenia developing after birth may aggravate injury because it is commonly associated with increased lung neutrophils resulting from pulmonary sequestration $(49,50)$.

Recent reviews have stressed the importance of inflammation as a major cause of lung injury in VLBW infants. Evidence cited in support of this hypothesis includes increased levels of antenatal cytokines in amniotic fluid (interleukins (IL)-1, -6, and -8) and cord serum (IL-6) and increased levels of postnatal cytokines (IL-6, TNF), eicosanoids (LTB4, TXB2), chemokines (IL-8, MIP-1), platelet activating factor, and neutrophils in the tracheal aspirates of infants who later develop CLD (7, 22, 51-54). The relative roles of antenatal infection (chorioamnionitis), late onset neonatal sepsis, the acute phase response, barotrauma, and the evolving lung disease itself are very difficult to dissect $(21,55,56)$. In particular the role of chorioamnionitis in CLD has been controversial. Although most studies have found a positive association, methodologic questions have been raised regarding comparability of birth weights, the definitions of both chorioamnionitis and CLD, the time periods studied, and geographic variation (1-3, 57). After adjustment for gestational age and birth weight for GA, we found histologic chorioamnionitis to be inversely related to CLD. This relationship lost significance when considered along with other risk factors in the multivariate analysis. Further analyses considering clinical and histologic chorioamnionitis subdivided by origin of inflammatory cells (maternal versus fetal) and severity of inflammation, failed to reveal any subtype that was positively correlated with CLD.

This study and others have identified white race as an independent risk factor for CLD (30). After stratification by race an interesting dichotomy was observed in the relationship between chorioamnionitis and CLD. Clinical chorioamnionitis was a borderline significant positive risk factor for CLD in white infants and severe fetal histologic chorioamnionitis showed a significant inverse relationship to CLD in nonwhite 
infants. Other measures of chorioamnionitis were also increased in white infants and decreased in nonwhite infants with CLD. These differences could not be explained by differences between black and white infants in early neonatal death, acute respiratory distress, duration of ventilation or oxygen supplementation, or intubation status on day 2 of life (early severe illness).

Other investigators have reported racial differences in the susceptibility of VLBW infants to lung disease. White infants are reported to have increased early RDS-related mortality, increased severity of neonatal illness (higher neonatal risk scores), and increased rates of asthma (58-60). Interestingly, a few recent studies have also found that the relationship between chorioamnionitis and neonatal complications such as cerebral palsy in VLBW infants may apply primarily to white infants (61)(J Grether, personal communication). Possible explanations for these differential effects include differing rates of co-morbidities such as severe acute illness, racial differences in cytokine responses or organ susceptibility to cytokines, and different postnatal responses arising secondary to differing in utero environments. Our preliminary data showing significant differences in maternal age, infertility, multiple pregnancy, antenatal care, delivery route, and genitourinary infections provide some support for the last explanation. This unanticipated racial disparity in the effect of chorioamnionitis on CLD deserves further study and might explain conflicting data from centers with differing ethnic and racial populations.

\section{CONCLUSION}

In conclusion, antenatal factors including gestational age at delivery, fetal growth restriction, and a pathologically defined subgroup of maternal preeclampsia modulated the risk of CLD. Chorioamnionitis did not appear to play a role in the population as a whole, but may have contributed to CLD in white infants. Other risk factors for CLD were all related to the neonatal course and included patent ductus arteriosus, pulmonary air leak, and, possibly, septicemia.

Acknowledgments. The authors thank Mark Schlucter, Ph.D., for statistical consultation, Nori Minich for performing the statistical analyses, and Debra Pierce for secretarial assistance.

\section{REFERENCES}

1. Watterberg KL, Demers L, Scott SM, Murphy S 1996 Chorioamnionitis and early lung inflammation in infants in whom bronchopulmonary dysplasia develops. Pediatrics 97:210-215

2. Matsuda T, Nakajima T, Hattori S, Hanatani K, Fukazawa Y, Kobayashi K, Fujimoto S 1997 Necrotizing funisitis: clinical significance and association with chronic lung disease in premature infants. Am J Obstet Gynecol 177:1402-1407

3. Kitajima H, Nakayama M, Miyano A, Shimizu A, Taniguchi T, Shimoya K, Matsuzaki N, Fujimura M 1992 Significance of chorioamnionitis. Early Hum Dev 29:125130

4. Lyon A 2000 Chronic lung disease of prematurity. The role of intra-uterine infection. Eur J Pediatr 159:798-802

5. Yoon BH, Romero R, Jun JK, Park KH, Park JD, Ghezzi F, Kim BI 1997 Amniotic fluid cytokines (interleukin-6, tumor necrosis factor-alpha, interleukin-1 beta, and interleukin-8) and the risk for the development of bronchopulmonary dysplasia. Am J Obstet Gynecol 177:825-30

6. Jobe AJ 1999 The new BPD: an arrest of lung development. Pediatr Res 46:641-643

7. Bancalari E 2000 Epidemiology and risk factors for the "new" bronchopulmonary dysplasia. NeoReviews 1:e2-e5
8. Hack M, Wilson-Costello D, Friedman H, Taylor GH, Schluchter M, Fanaroff AA 2000 Neurodevelopment and predictors of outcomes of children with birth weights of less than $1000 \mathrm{~g}$ : 1992-1995. Arch Pediatr Adolesc Med 154:725-731

9. Redline RW, Wilson-Costello D, Borawski E, Fanaroff AA, Hack M 1998 Placental lesions associated with neurologic impairment and cerebral palsy in very low birth weight infants. Arch Pathol Lab Med 122:1091-1098

10. Wilson-Costello D, Borawski E, Friedman H, Redline RW, Fanaroff AA, Hack M 1998 Perinatal correlates of cerebral palsy and other neurologic impairment among very low birthweight children. Pediatrics 102:315-322

11. Dombrowski MP, Wolfe HM, Brans YW, Saleh AA, Sokol RJ 1992 Neonatal morphometry. Relation to obstetric, pediatric, and menstrual estimates of gestational age. Am J Dis Child 146:852-856

12. Genest DR, Ringer S Placental findings correlate with neonatal death in extremely premature infants (24-32 weeks): a study of 150 cases (Abstract). Lab Invest 1993:68:126A

13. Korhonen P, Koivisto AM, Ikonen S, Laippala P, Tammela O 1999 Very low birthweight, bronchopulmonary dysplasia and health in early childhood. Acta Paediatr $88: 1385-1391$

14. Jacob SV, Coates AL, Lands LC, MacNeish CF, Riley SP, Hornby L, Outerbridge EW, Davis GM, Williams RL 1998 Long-term pulmonary sequelae of severe bronchopulmonary dysplasia. J Pediatr 133:193-200

15. Northway WH, Jr., Moss RB, Carlisle KB, Parker BR, Popp RL, Pitlick PT, Eichler I, Lamm RL, Brown BW Jr. 1990 Late pulmonary sequelae of bronchopulmonary dysplasia. N Engl J Med 323:1793-1799

16. Singer L, Yamashita T, Lilien L, Collin M, Baley J 1997 A longitudinal study of developmental outcome of infants with bronchopulmonary dysplasia and very low birth weight. Pediatrics 100:987-993

17. Redline R, Wilson-Costello D, Borawski E, Fanaroff A, Hack M The relationship between placental and other perinatal risk factors for neurologic impairment in very low birth weith children. Pediatr Res 2000;47:721-726.

18. Stocker JT 1988 Congenital and developmental diseases. In: Dail DH, Hammer SP (eds) Pulmonary Pathology. Springer-Verlag, Heidelberg, p 77

19. Rojas MA, Gonzalez A, Bancalari E, Claure N, Poole C, Silva-Neto G 1995 Changing trends in the epidemiology and pathogenesis of neonatal chronic lung disease. J Pediatr 126:605-610

20. Charafeddine L, D'Angio CT, Phelps DL 1999 Atypical chronic lung disease patterns in neonates. Pediatrics 103:759-765

21. Jobe AH, Ikegami M 1998 Mechanisms initiating lung injury in the preterm. Early Hum Dev 53:81-94

22. Speer CP 1999 Inflammatory mechanisms in neonatal chronic lung disease. Eur J Pediatr 158 (Suppl 1):S18-22

23. Palta M, Sadek M, Barnet JH, Evans M, Weinstein MR, McGuinness G, Peters ME, Gabbert D, Fryback D, Farrell P 1998 Evaluation of criteria for chronic lung disease in surviving very low birth weight infants. J Pediatr 132:57-63

24. Shannan AT, Dunn MS, Ohlsson A, Lennox K, Hoskins EM 1998 Abnormal pulmonary outcomes in premature infants: prediction from oxygen requirement in the neonatal period. J Pediatr 82:527-532

25. Garland JS, Buck RK, Allred EN, Leviton A 1995 Hypocarbia before surfactant therapy appears to increase bronchopulmonary dysplasia risk in infants with respiratory distress syndrome. Arch Pediatr Adolesc Med 149:617-622

26. Marshall DD, Kotelchuck M, Young TE, Bose CL, Kruyer L, O'Shea TM 1999 Risk factors for chronic lung disease in the surfactant era: a North Carolina populationbased study of very low birth weight infants. North Carolina Neonatologists Association Pediatrics 104:1345-1350

27. Banks BA, Stouffer N, Cnaan A, Ning Y, Merrill JD, Ballard RA, Ballard PL; North American Thyrotropin-Releasing Hormone Trial Collaborators 2001 Association of plasma cortisol and chronic lung disease in preterm infants. Pediatrics 107:494-498

28. Watterberg KL, Scott SM, Backstrom C, Gifford KL, Cook KL 2000 Links between early adrenal function and respiratory outcome in preterm infants: airway inflammation and patent ductus arteriosus. Pediatrics 105:320-324

29. Richardson DK, Corcoran JD, Escobar GJ, Lee SK. SNAP-II and SNAPPE-II 2001 Simplified newborn illness severity and mortality risk scores. J Pediatr 138:92-100

30. Palta M, Gabbert D, Weinstein MR, Peters ME 1991 Multivariate assessment of traditional risk factors for chronic lung disease in very low birth weight neonates. The Newborn Lung Project J Pediatr 119:285-292

31. Ballard RA, Ballard PL, Cnaan A, Pinto-Martin J, Davis DJ, Padbury JF, Phibbs RH, Parer JT, Hart MC, Mannino FL, Sawai SK 1998 Antenatal thyrotropin-releasing hormone to prevent lung disease in preterm infants. North American ThyrotropinReleasing Hormone Study Group. N Engl J Med 338:493-498

32. Gonzalez A, Sosenko IR, Chandar J, Hummler H, Claure N, Bancalari E 1996 Influence of infection on patent ductus arteriosus and chronic lung disease in premature infants weighing 1000 grams or less. J Pediatr 128:470-478

33. Stevenson DK, Verter J, Fanaroff AA, Oh W, Ehrenkranz RA, Shankaran S, Donovan EF, Wright LL, Lemons JA, Tyson JE, Korones SB, Bauer CR, Stoll BJ, Papile LA 2000 Sex differences in outcomes of very low birthweight infants: the newborn male disadvantage. Arch Dis Child Fetal Neonatal Ed 83:F182-185

34. Milner AD, Marsh MJ, Ingram DM, Fox GF, Susiva C 1999 Effects of smoking in pregnancy on neonatal lung function. Arch Dis Child Fetal Neonatal Ed 80:F8-14

35. Vergani P, Ghidini A, Locatelli A, Cavallone M, Ciarla I, Cappellini A, Lapinski RH 1994 Risk factors for pulmonary hypoplasia in second-trimester premature rupture of membranes. Am J Obstet Gynecol 170:1359-1364

36. Baud O, Zupan V, Lacaze-Masmonteil T, Audibert F, Shojaei T, Thebaud B, Ville Y, Frydman R, Dehan M 2000 The relationships between antenatal management, the cause of delivery and neonatal outcome in a large cohort of very preterm singleton infants. Br J Obstet Gynaecol 107:877-884 
37. Bardin C, Zelkowitz P, Papageorgiou A 1997 Outcome of small-for-gestational age and appropriate-for-gestational age infants born before 27 weeks of gestation. Pediatrics 100:E4

38. Sung IK, Vohr B, Oh W 1993 Growth and neurodevelopmental outcome of very low birth weight infants with intrauterine growth retardation: comparison with contro subjects matched by birth weight and gestational age. J Pediatr 123:618-624

39. Bernstein IM, Horbar JD, Badger GJ, Ohlsson A, Golan A 2000 Morbidity and mortality among very-low-birth-weight neonates with intrauterine growth restriction. The Vermont Oxford Network Am J Obstet Gynecol 182:198-206

40. Hawdon JM, Ward Platt MP 1993 Metabolic adaptation in small for gestational age infants. Arch Dis Child 68:262-268

41. Metcoff J 1994 Clinical assessment of nutritional status at birth. Fetal malnutrition and SGA are not synonymous. Pediatr Clin North Am 41:875-891

42. Bustos R, Kulovich MV, Gluck L, et al 1979 Significance of phosphatidylglycerol in amniotic fluid in complicated pregnancies. Am J Obstet Gynecol 133:899-903

43. Kim CR, Vohr BR, Oh W 1996 Effects of maternal hypertension in very-low-birthweight infants. Arch Pediatr Adolesc Med 150:686-691

44. Khong TY 1991 Acute atherosis in pregnancies complicated by hypertension, growth retardation, and diabetes melitus. Arch Pathol Lab Med 115:722-725

45. Redman CWG, Sargent IL 2000 Placental debris, oxidative stress and pre-eclampsia. Placenta 21:597-602

46. Morita H, Mizutori M, Takeuchi K, Motoyama S, Maruo T 2001 Abundant expression of platelet-derived growth factor in spiral arteries in decidua associated with pregnancyinduced hypertension and its relevance to atherosis. Eur J Endocrinol 144:271-276

47. Salafia C, Starzyk K, Ossandon M, et al 1996 Lipoprotein (a) deposition in the uteroplacental bed distinguishes normal and preeclamptic pregnancies. Am J Obstet Gynecol 174:363

48. Gray PH, Rodwell RL 1999 Neonatal neutropenia associated with maternal hypertension poses a risk for nosocomial infection. Eur J Pediatr 158:71-73

49. Ferreira PJ, Bunch TJ, Albertine KH, Carlton DP 2000 Circulating neutrophil concentration and respiratory distress in premature infants. J Pediatr 136:466-472

50. Carlton DP, Albertine KH, Cho SC, Lont M, Bland RD 1997 Role of neutrophils in lung vascular injury and edema after premature birth in lambs. J Appl Physiol $83: 1307-1317$
51. Yoon BH, Jun JK, Romero R, Park KH, Gomez R, Choi JH, Kim IO 1997 Amniotic fluid inflammatory cytokines (interleukin-6, interleukin-1 beta, and tumor necrosis factor-alpha), neonatal brain white matter lesions, and cerebral palsy. Am J Obstet Gynecol 177:19-26

52. Yoon BH, Romero R, Kim KS, Park JS, Ki SH, Kim BI, Jun JK 1999 A systemic fetal inflammatory response and the development of bronchopulmonary dysplasia. Am J Obstet Gynecol 181:773-779

53. Nupponen I, Venge P, Pohjavuori M, Lassus P, Andersson S 2000 Phagocyte activation in preterm infants following premature rupture of the membranes or chorioamnionitis. Acta Paediatr 89:1207-1212

54. Koyama N, Ogawa Y 1999 Elevated platelet activating factor in the tracheal aspirate at birth and signs of intra-uterine inflammation in infants with neonatal pulmonary emphysema. Eur J Pediatr 158:858-862

55. Speer CP, Groneck P 1998 Oxygen radicals, cytokines, adhesion molecules and lung injury in neonates. Semin Perinatol 3:219-228

56. Dos Santos CC, Slutsky AS 2000 Invited review: mechanisms of ventilator-induced lung injury: a perspective. J Appl Physiol 89:1645-1655

57. Yoon BH, Romero R, Kim CJ, Jun JK, Gomez R, Choi JH, Syn HC 1995 Amniotic fluid interleukin-6: a sensitive test for antenatal diagnosis of acute inflammatory lesions of preterm placenta and prediction of perinatal morbidity. Am J Obstet Gynecol 172:960-970

58. Brooks AM, Byrd RS, Weitzman M, Auinger P, McBride JT 2001 Impact of low birth weight on early childhood asthma in the United States. Arch Pediatr Adolesc Med 155:401-406

59. Ranganathan D, Wall S, Khoshnood B, Singh JK, Lee KS 2000 Racial differences in respiratory-related neonatal mortality among very low birth weight infants. J Pediatr $136: 454-459$

60. Berman S, Richardson DK, Cohen AP, Pursley DM, Lieberman E 2001 Relationship of race and severity of neonatal illness. Am J Obstet Gynecol 184: $668-672$

61. Schieve LA, Handler A 1996 Preterm delivery and perinatal death among black and white infants in a Chicago-area perinatal registry. Obstet Gynecol 88: $356-363$ 